\title{
Research on the Artistic Conception Creation of National Dance Works
}

\author{
Jingxian Liu \\ Shandong Management University, Jinan, Shandong, China \\ Email: liujingxian201711@163.com
}

Keywords: National dance works, Artistic conception analysis, Artistic conception creation

\begin{abstract}
Artistic conception is an important part of Chinese classical art creation, which is the highest realm in the process of artistic pursuit, and also the highest requirement of dance art creation. Especially in the new era, art presents a trend of diversified development, and the creation of artistic conception in national dance works has become an important embodiment of its own artistic attainments. This paper mainly analyzes the related content of national dance artistic conception, and studies the artistic conception creation of national dance works, hoping to provide some reference for the creation of national dance works in China.
\end{abstract}

\section{Introduction}

Dance is an art form to convey and spread specific cultural connotation and emotion through specific body movements. It stresses the artistic form and atmosphere brought by artistic conception creation. The artistic conception in dance works can transmit the connotation and thought of dance through the atmosphere of the intersection of virtual and real, and the blend of emotion and scene. It usually uses exaggeration, contrast, symbol and other ways to show the rich connotation and spirit of dance language, which belongs to the combination of objective reality and subjective emotion. The creation and pursuit of artistic conception in the creation of national dance works has been paid special attention, which is an important way to better reflect the connotation and level of dance. The creation of national dance works is the combination of national spirit inheritance and synchronous development of the times, and it plays an important role in the embodiment of artistic sense of works.

\section{Analysis on the Artistic Conception of National Dance}

Artistic conception is the highest pursuit of dance art, and is an important part of the aesthetic system from ancient times to the present. Art creators rely on their works to convey and express their emotions. National dance works convey not only the creator's thoughts and emotions, but also the national spirit, connotation and cultural heritage. The creation of artistic conception in national dance works can make the dance works more complete, and the dance image more abstract or real. Dance works can be displayed by the way of virtual-real interaction and emotional blending, so as to promote the artistic value of dance works to a higher position. The artistic conception of national dance can be understood and analyzed from the following aspects.

\subsection{Analysis on Artistic Conception of Mentality}

Mentality is the manifestation and transmission of dancers' psychological activities through dance. Mentality has complex characteristics. It is the integration of people's complex emotions with dance works. Emotional communication is easily affected by environmental factors. Therefore, it can be concluded that the artistic conception of mentality is often forms and content related to emotions.

\subsection{Analysis on Artistic Conception of Ecological Environment}

The artistic conception construction of ecological environment refers to the combination and design of dance action elements in dance works to show the different characteristics of natural 
ecology. The creation of ecological artistic conception in dance works is a special form of artistic conception creation. There are mainly two ways to show it. First, dancers can use the biological action and image of nature to create the artistic conception of ecological environment, mainly through grasping the main image characteristics of natural creatures, using dance action elements and dance language to show them more vividly. Second, to create artistic conception of natural landscape, dance works can use specific costumes as carriers to reflect the natural landscape flavor and characteristics, so that the audience can feel and perceive the rich emotions of nature and human world through its artistic conception while appreciating the dance art.

\subsection{Analysis on Artistic Conception of Spirit Communication}

The concrete embodiment of spirit communication in dance works is to use emotional communication and convey to form artistic conception form. In the process of spirit communication, the artistic conception is to blend the emotion and the scene, and constantly lead the dance connotation to show one by one through the relationship between people and things, people and the scene.

\section{Research on the Artistic Conception Creation of National Dance Works}

\subsection{Artistic Conception Creation of Dance Action}

Theme and materials are the basic elements of the creation of national dance works. The action design, innovation and the connection between different actions in dance works are the important links and components of national dance. Independent and single dance movement will not have the function of creating artistic conception. Only by making different dance movements coherently and organically connected can it have artistic conception. In the process of creating artistic conception in dance action design, we need to combine dance style and rhythm characteristics, and reflect different dance styles through the costumes and decorations with national elements worn by dancers, so as to lay a basic objective foundation and conditions for the display of dance artistic conception.

\subsubsection{Artistic Conception Creation of Style}

Style is the primary consideration of dance creators in the process of national dance movement design, and it is the embodiment of the main characteristics of dance movement. Style creation is an important internal feature of national dance and a basic element in the process of dance creation. According to different regions and nationalities, the styles of national dances are quite different, so the artistic conception of national dances has its own characteristics. In the process of dance action design, in addition to considering the style, we should also have the innovative consciousness and spirit, and look for more materials and dance elements to apply them to the artistic conception creation of dance works. For example, taking the Hui dance "Three Colors of Water" as an example, the dance creators use the broken shaking-head action with the characteristics of the national dance style in the process of dance action design, and on this basis, they use the remake downward bending, stretching, shaking and back flashing broken shaking head to innovate, which not only maintain the basic style of the Hui national dance, but also make the dance movements have a more in-depth development in the range and strength. Through shaking and other dance movements, it extends to all parts of the dancer's body, and then vividly shows the image of Hui girls with noble temperament. Through the combination of traditional style and innovative movements, the artistic conception of dance has the characteristics of ambivalence, virtual-reality interaction, making the dance appreciators deeply understand the ethnic customs conveyed by the Hui dance.

\subsubsection{Artistic Conception Creation of Rhythm}

In the process of national dance movement design, dance creators also need to explore and study the artistic conception of dance combined with the characteristics of rhythm. Rhythm has essential characteristics in the artistic conception creation of national dance works, and it plays a decisive role in the artistic height of dance artistic conception. In dance design, we can make full use of the speed, retraction, transformation of the actions, the cohesion between the actions and the design of 
the structure level to reflect the rhythm. The dance movements and cohesion of dynamics can be combined with rhythm to create and transmit the artistic conception of dance. Different rhythms are the soul of the structure of national dance. National dance uses its dance movements with strong national rhythms and charm to show the unique national characteristics. The rhythm of lifting and sinking in Korean dance and the rhythm of tremor are the embodiment of the unique rhythm of national dance. Using the unique dance rhythm of different nationalities to show their dance characteristics is an important way to create the artistic conception of national dance.

\subsection{Artistic Conception Creation of Dance Composition}

The composition in the process of dance design is an important dance language, an important way of its presentation on the stage, and a dynamic structure of space and time transformation in dance works. It usually refers to the common combination of the dancer's movement track in space and the picture presented in the performance process. Any dance needs to use the stage space for artistic display, so the stage is an important part of dance works, and it is an important basis for creating the artistic conception of dance. In the process of dance design, dance communication usually refers to the plane and three-dimensional composition.

\subsubsection{Design of Plane Composition}

National dance belongs to the objective form of dance, has static and dynamic expressions, so the stage plane composition plays an important role in it. It mainly refers to the relationship between the dancer and the stage in terms of spatial position. Different positions of the stage have their specific meaning and dance expression. Therefore, dance creators need to combine the plane composition to better show the artistic conception of dance. The center of the stage and the center of the left and right sides are the most frequent places for dancers in dance performance activities, and they are also the important display positions of dance plots. The rear positions on the left and right sides of the stage are far away from the audience, and the general design is the secondary part of dance, character design, etc. That is to say, from the perspective of stage orientation, its expressive power radiates from the center of the stage to its edge, and constantly weakens from strong to weak, and the artistic conception of dance presented by it is also looming. Therefore, in the process of stage plane composition design, we need to use the structural characteristics of point, direction and plane to design and create different artistic conception.

\subsubsection{Design of Three-Dimensional Composition}

The three-dimensional composition includes the movement track between the points and lines formed by the dancer's own position, as well as the three-dimensional structure of height, depth and width and the composite graphics formed by the dancer. In order to achieve a more complete three-dimensional composition of national dance, it is necessary to combine the three-dimensional structure of the space formed by dance movements, and master the relationship between different elements, such as symmetry and balance, contrast and concentration, contained in dance movements. Symmetry and balance, a common creation method in the three-dimensional composition design of national dance, can create a more stable and harmonious dance artistic conception, and is conducive to the presentation and maintenance of the authenticity and three-dimensional sense in the dance picture. Contrast and concentrated three-dimensional composition is also a common artistic conception design method. It uses an intense contrast to produce visual impact, mobilizes the audience's emotions and creates a more real and vivid artistic conception.

\section{Conclusion}

To sum up, we can understand that the artistic conception of dance is the highest pursuit in the creation process of dance works and an important embodiment of the artistic value of dance. Combined with the specific dance style and rhythm of national dance, the design and combination of dance movements can more clearly show the characteristics of national dance and create a stronger national artistic conception. Fully combining the space characteristics of the stage space in 
creating the artistic conception of dance, and integrating it into the design of national dance can present different artistic conception of dance, and bring more real, vivid, concrete or abstract artistic conception to the audience. National dance works show the creator's emotion, thought and connotation, but also national characteristics, culture and history. Therefore, strengthening the pursuit of artistic conception of dance can enhance its artistic value.

\section{References}

[1] Li Yilin. Research on the Application of Props in the Creation of Contemporary Chinese Folk Dance Works -- Application of Props in the Creation of Dai Dance Works. Popular Literature and Art, no.05, pp.246-250, 2019.

[2] Ren Qi. On the Creation of Artistic Conception of Dance. Sichuan Drama, no.08, pp.112-114, 2017.

[3] Jing Yuhuan. Artistic Conception Creation of Folk Dance Works. Drama House, no.14, pp.164, 2017. 